\title{
Patient with gastric rupture due to bag ventilation underwent conservative treatment combined with endoscopic observation
}

\author{
Hirofumi Harima (ㄷ, ${ }^{1}$ Seiji Kaino, ${ }^{2}$ Kazutoshi Sanuki, ${ }^{3}$ Isao Sakaida ${ }^{2}$
}

'Department of

Gastroenterology, Saiseikai Shimonoseki General Hospital, Shimonoseki, Japan

${ }^{2}$ Department of

Gastroenterology and Hepatology, Yamaguchi University Graduate School of Medicine, Ube, Japan

${ }^{3}$ Department of Gastroenterology, Ube Industries Central Hospital, Ube, Japan

\section{Correspondence to} Dr Hirofumi Harima; h-harima@simo.saiseikai.or.jp

Accepted 25 January 2021
Check for updates

(c) BMJ Publishing Group Limited 2021. No commercial re-use. See rights and permissions. Published by BMJ.

To cite: Harima H, Kaino $\mathrm{S}$, Sanuki K, et al. BMJ Case Rep 2021;14:e240116. doi:10.1136/bcr-2020240116

\section{DESCRIPTION}

An 81-year-old woman was brought to our hospital with septic shock due to severe acute cholangitis. Her blood pressure was $61 / 39 \mathrm{~mm} \mathrm{Hg}$, and her $\mathrm{SpO}_{2}$ was $99 \%$ with $6 \mathrm{~L} /$ min oxygen administration. CT showed common bile duct stones and abscess formation in the liver bed. We decided to perform urgent endoscopic biliary drainage because her blood pressure and $\mathrm{SpO}_{2}$ improved with an intravenous drip. We administered $1.0 \mathrm{mg}$ of midazolam to achieve sedation. Subsequently, the patient became hypoxic. We replaced a nasal oxygen cannula with an oxygen mask and administered $0.5 \mathrm{mg}$ of flumazenil. Nevertheless, her $\mathrm{SpO}_{2}$ decreased below the sensitivity limits of the pulse oximeter. We started bag ventilation at a rate of 10-12 bpm. We continued bag ventilation for approximately $10 \mathrm{~min}$ because her hypoxia did not improve until intubation. After her hypoxia was improved, we performed endoscopy, which showed bleeding from a gastric laceration on the lesser curvature (figure 1A). We first conducted biliary stenting because X-ray images did not show free air. After successful biliary stenting, we attempted endoscopic suturing; however, we abandoned this procedure because her systolic blood pressure decreased below $60 \mathrm{~mm} \mathrm{Hg}$. We completed endoscopy and placed a nasogastric tube. After the procedure, CT revealed free air in the abdominal cavity (figure 1B). We diagnosed the patient with gastric rupture due to bag ventilation. We considered that she was unsuitable for surgery because of the risk of death during surgery. We conducted conservative treatments including gastric decompression via a nasogastric tube and administration of proton pump inhibitors, antibiotics and many blood transfusions. One week later, the gastric bleeding stopped spontaneously with improvement in cholangitis. One month later, endoscopy revealed spontaneous closure of the gastric laceration and discolouration of the gastric mucosa (figure 2A). We considered that discolouration occurred as a result of gastric ischaemia. Two months later, endoscopy showed scarring of the gastric laceration (figure $2 \mathrm{~B}$ ). The discolouration of the gastric mucosa was recovered. The patient was discharged after successful endoscopic removal of common bile duct stones.

Gastric rupture is a rare complication of bag ventilation ${ }^{1}$ and is considered to be caused by gastric distention due to air inflow. Glossoptosis or bronchial foreign bodies during ventilation often cause distention of the stomach. Stomach distention causes twisting of the cardia and pylorus, making it difficult to discharge gas from the stomach and further increasing intragastric pressure. Gastric rupture could occur if the gastric pressure exceeds $120-150 \mathrm{~mm} \mathrm{Hg}{ }^{2}$ To prevent gastric rupture, reliable airway management and prompt tracheal intubation after bag ventilation are required. ${ }^{3}$ When gastric rupture occurs, emergency surgery is generally performed, but conservative treatment can be an option because gastric laceration may close

\section{Patient's perspective}

I had spent 2 weeks in intensive care unit, but recovered with conservative treatment. When I was discharged, I was very well without any symptoms.
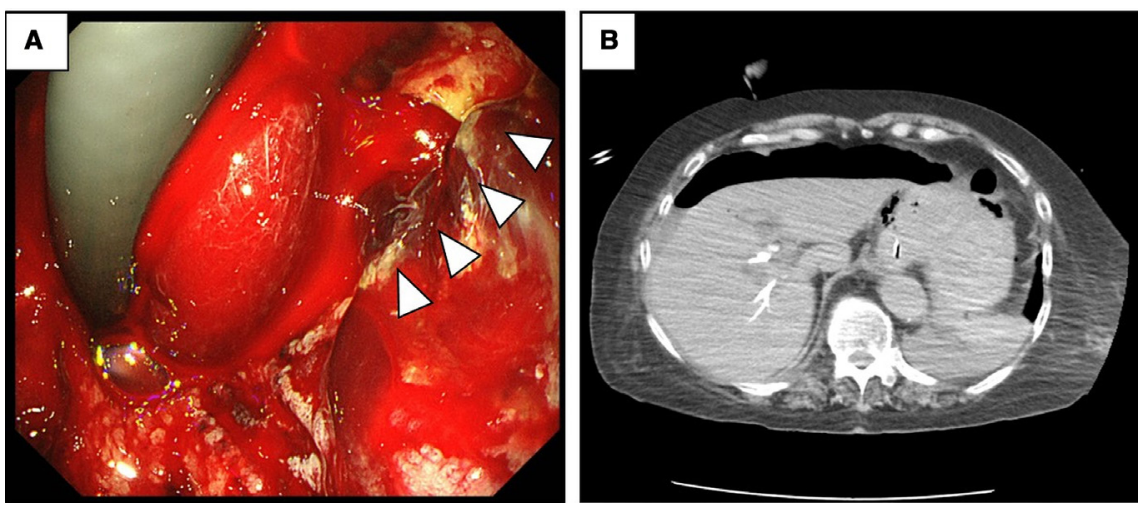

Figure 1 (A) Endoscopic view of the stomach after bag ventilation and intubation. Bleeding from a gastric laceration on the lesser curvature is shown (arrowheads). (B) CT after the endoscopic procedure. Free air in the abdominal cavity is shown. 

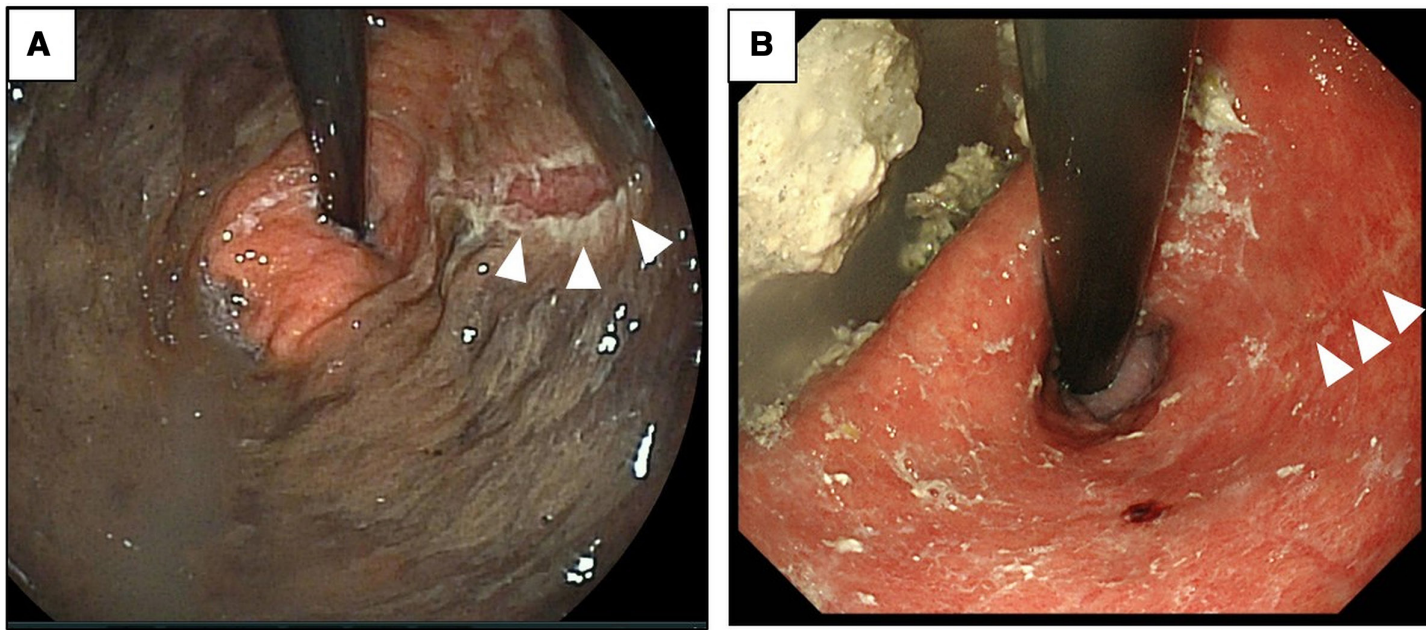

Figure 2 Endoscopic views of the stomach after conservative treatment for gastric rupture. (A) One month later. Spontaneous closure of the gastric laceration is shown (arrowheads). Discolouration of the gastric mucosa due to ischaemia is also shown. (B) Two months later. Scarring of the gastric laceration is shown (arrowheads). Recovery of the discolouration of the gastric mucosa is also shown.

\section{Learning points}

- Although rare, bag ventilation could cause gastric rupture.

- When gastric rupture occurs, emergency surgery is generally performed, but conservative treatment can be an option.

- A gastric laceration immediately after the rupture was observed accidentally.
Funding The authors have not declared a specific grant for this research from any funding agency in the public, commercial or not-for-profit sectors.

Competing interests None declared.

Patient consent for publication Obtained

Provenance and peer review Not commissioned; externally peer reviewed.

\section{ORCID iD}

Hirofumi Harima http://orcid.org/0000-0003-0406-0345

\section{REFERENCES}

1 Zhou G-J, Jin P, Jiang S-Y. Gastric perforation following improper cardiopulmonary resuscitation in out-of-hospital cardiac arrest. Pak J Med Sci 2020:36:296-8.

2 Spoormans I, Van Hoorenbeeck K, Balliu L, et al. Gastric perforation after cardiopulmonary resuscitation: review of the literature. Resuscitation 2010:81:272-80

3 Malik SM, Rockacy M, Al-Khafaji A. Bleeding after bagging. diagnosis: gastric rupture and massive pneumoperitoneum secondary to barotrauma from bag ventilation. Gastroenterology 2011;141:e16-17.

4 Arai Y, Honjo S, Shimizu S, et al. Traumatic gastric perforation associated with cardiopulmonary resuscitation: a case report. Yonago Acta Med 2017;60:204-8.

Copyright 2021 BMJ Publishing Group. All rights reserved. For permission to reuse any of this content visit

https://www.bmj.com/company/products-services/rights-and-licensing/permissions/

BMJ Case Report Fellows may re-use this article for personal use and teaching without any further permission.

Become a Fellow of BMJ Case Reports today and you can:

- Submit as many cases as you like

- Enjoy fast sympathetic peer review and rapid publication of accepted articles

- Access all the published articles

- Re-use any of the published material for personal use and teaching without further permission

\section{Customer Service}

If you have any further queries about your subscription, please contact our customer services team on +44 (0) 2071111105 or via email at support@bmj.com.

Visit casereports.bmj.com for more articles like this and to become a Fellow 